\title{
Effect of Industrial Infrastructure, Nature of Disease and Animal Demographics on Surveillance Strategies in Poultry
}

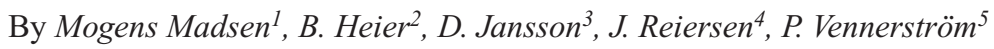 \\ ${ }^{1}$ Danish Veterinary Laboratory, 2 Hangøvej, DK-8200 Århus N., Denmark, ${ }^{2}$ Veterinærinstituttet, Boks 8156 \\ dep., NO-0033 Oslo, Norway, ${ }^{3}$ National Veterinary Institute, P.O. Box 7073, SE-75007 Uppsala, Sweden, \\ ${ }^{4}$ Tilraunastod Haskola Islands, Keldum v/ Vesturlandsveg, IL-110 Reykjavik, Iceland, ${ }^{5}$ EELA, P.O. Box 368, \\ FIN-00231 Helsinki, Finland.
}

The surveillance and control of poultry diseases in the Nordic countries present a long and to a large degree successful story which places the Nordic countries in a position as being largely free of most of the serious poultry diseases that constitutes a menace and an obstacle to effective and economically viable poultry production world-wide.

The surveillance and control of zoonotic agents in poultry equally place the Nordic countries in a category of its own. The achievements obtained within this area have provided the industry with an advantageous position on the domestic and export markets, in particular in relation to the EU where Finland and Sweden have been able to maintain special status and guarantees for imported poultry products.

The control strategy adopted for both statutory poultry diseases and zoonotic pathogens in
Nordic poultry production has from the very beginning been based on surveillance and stamping-out of infected flocks while vaccination strategies never have been adopted to a significant effect.

In terms of biosecurity, the geographical location of Nordic poultry production with a climate necessitating indoor production in closed units probably has provided the Nordic countries with an advantage compared to production in warmer climates with open-house production facilities.

In the paper, the disease situation with reference to statutory poultry diseases and zoonotic agents in each of the Nordic countries is reviewed, the organisation of control programmes described, and sampling and testing procedures presented and discussed. 